\title{
A review of intensity data banks online
}

\author{
Giuliana Rubbia \\ Istituto Nazionale di Geofisica e Vulcanologia, Sezione di Milano, Italy
}

\begin{abstract}
The investigation of the records of past earthquakes in Europe and in other countries of the world produced in recent years a large amount of information, such as historical seismicity studies, earthquake catalogues and collections of intensity data points. The rapid growth of computerized information systems allowed for management of data in digital form, while the evolution of Information and Communication Technologies initiated a new era of sharing, transferring and disseminating the output of this investigation. This paper outlines the availability and use of collections of intensity data points which are increasingly being offered to users through Internet such as: DOM and CFTI, Italy; SISFRANCE, France; ECOS, Switzerland; EMID, a starting point towards a European-Mediterranean Intensity Database; NGDC/NOAA database, US; CERESIS catalogue, South America.
\end{abstract}

Key words earthquake - intensity - database online

\section{Introduction}

The boost that historical seismology has been given in the last twenty years, the rapid development of Information and Communication Technology since the mid 90s and the will to invest in information dissemination initiatives allow us to have at our disposal a wealth of information about long-term seismicity over the Internet.

This information consists of several categories; a preliminary inventory performed in the framework of the initiatives for the dissemination of long-term seismicity data of the European Mediterranean Seismological Centre EMSC/CSEM lists dozens of pointers to online resources provided by more than twenty institutions in the European-Mediterranean area. These resources vary from seismicity maps and lists of main earthquakes to full catalogues and

Mailing address: Dr. Giuliana Rubbia, Istituto Nazionale di Geofisica e Vulcanologia, Sezione di Milano, Via E. Bassini 15, 20133 Milano, Italy; e-mail: rubbia@mi.ingv.it databases of primary data, out of which the category most represented is earthquake catalogue (http://emidius.mi.ingv.it/EMSC-KNM/).

When dealing with online intensity databanks, that is collections of Intensity Data Points - IDPs, bearing at least time, location (place-name and coordinates) and intensity of sites, we see that in Europe only three countries have consistent, online accessible sets of intensity data: Italy, France and Switzerland.

IDPs collections are of unquestionable value: on the one hand they expand the information synthesized in earthquake catalogues, allowing to access the reliability of the catalogue records themselves, and therefore to better understand long-term seismicity, and on the other, they serve as input for further analysis, such as seismic hazard evaluation; IDPs can be profitably used to determine preliminary models of seismogenic sources and calibrate seismic hazard estimates; for example see respectively Gasperini et al. (1999) and Mucciarelli et al. (2000), exploiting the Italian intensity databases described in this paper.

The compilation of an intensity database is an exacting work, which requires formalised and uniform procedures in analysing sources - historical records - and in assessing parameters. More- 
Table I. Online available intensity databanks.

\begin{tabular}{|c|c|c|c|c|c|}
\hline $\begin{array}{l}\text { Year of release } \\
\text { online }\end{array}$ & Data bank & Institution & Area & Number of IDPs & Time-span \\
\hline 1997 & DOM & INGV & Italy & 37000 & $1000-1980$ \\
\hline 1999 & CFTI & INGV & Italy & 31047 & $-461-1990$ \\
\hline 2001 & SISFRANCE & $\begin{array}{l}\text { BRGM, EDF, } \\
\text { IPSN }\end{array}$ & France & 88000 & 463-2001 \\
\hline 2002 & $\begin{array}{l}\text { SISFRANCE } \\
\text { Antilles }\end{array}$ & BRGM & Antilles & 4900 & $1465-2001$ \\
\hline 2002 & ECOS & SED & Switzerland & 26061 & $250-2001$ \\
\hline 1997 & US & NGDC/NOAA & United States & 157015 & $1638-1985$ \\
\hline 1996 & CERESIS & CERESIS & South America & 16318 & $1520-1981$ \\
\hline 1999 & EMID (*) & INGV & Europe & $\left(^{*}\right)$ & $\left(^{*}\right)$ \\
\hline
\end{tabular}

(*) In progress.

over, once the database is compiled, according to homogeneous criteria and reproducible procedures, its quality has to be preserved in the online release: further efforts and investments are required in its development and maintenance.

The paper presents those datasets which are currently available in Internet (table I): DOM, an intensity database of damaging earthquake in the Italian area and the Catalogue of Strong Italian Earthquakes; SISFRANCE accounting for France, French Antilles and the Caribbean; ECOS, the Earthquake Catalogue Of Switzerland; the United States Earthquake Intensity Database; the intensity catalogue of South America, by Centro Regional de Sismología Para America del Sur, and the EuropeanMediterranean Intensity Database - EMID; for each of them, it describes which data are available and how they are presented to the users.

\section{DOM, an intensity database of damaging earthquakes in the Italian area}

DOM, an intensity database of damaging earthquakes in the Italian area (Monachesi and Stucchi, 1997) has been compiled within the framework of investigations of the National Group for Defence from Earthquakes of Italy
(Gruppo Nazionale per la Difesa dai Terremoti, GNDT) during the years 1988-1996. It consists of the intensity data derived from studies produced by GNDT itself and by other institutions in Italy (ENEA, ENEL, ING), which have been geo-referenced and made homogeneous according to a given format. This dataset was used to compile the parametric catalogue of damaging earthquakes in the Italian area, NT (Camassi and Stucchi, 1997), accounting for one thousand events. DOM was published over the Internet as an online searchable database in 1997, and progressively updated during the following two years (Padula and Rubbia Rinaldi, 1999) and it is presently run by INGV at http://emidius.mi.ingv.it/DOM/

DOM stores 37000 intensity data points, referring to 904 earthquakes in the time window 1000-1980 and more than 10000 localities, 935 intensity maps, and relies on 81 macroseismic studies.

Two types of query are available: query by earthquake, to extract the intensity data points, and by locality, to provide seismic histories at sites.

In the query by earthquake, users locate the earthquake of interest scrolling the parametric catalogue; a click on this record fires the visualization of the intensity data points as a list, and on an interactive map. The list of observations include locality name, coordinates, intensity at site in 


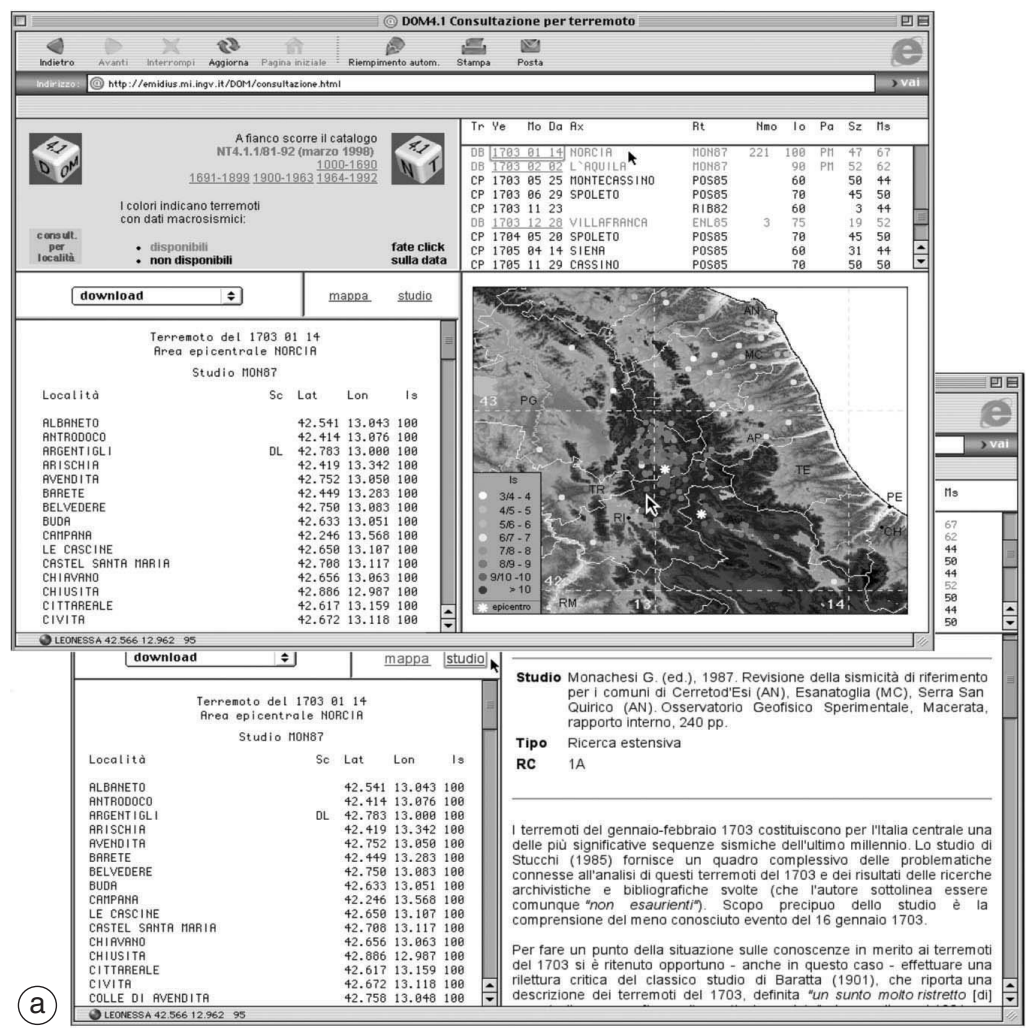

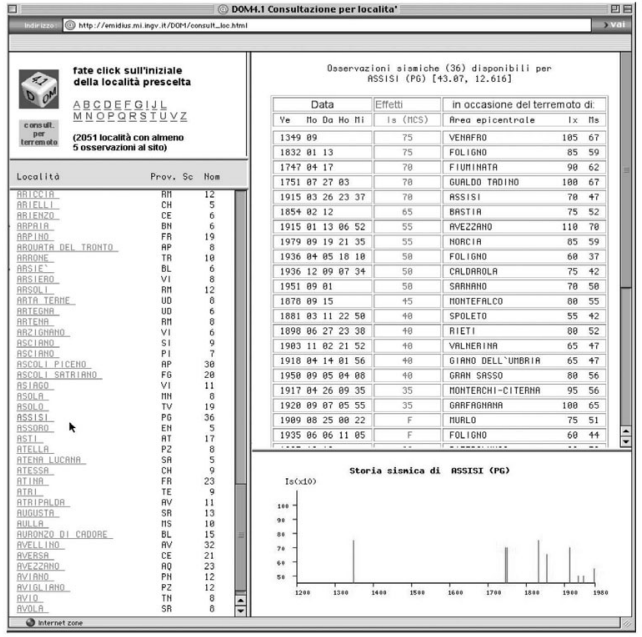

(b)

Fig. 1a,b. DOM query by earthquake (a), by locality (b).
MCS scale, and a parameter which codifies special cases with regard to the assessment of intensity and of coordinates (fig. 1a).

Each intensity map consists of different levels of information: beyond the intensity data points and the epicentre, a Digital Elevation Model (DEM) with a regular grid of $250 \mathrm{~m}$, administrative boundaries, hydrography, main cities and locality names are displayed; each map is centred on the epicentre, covering an area the extent of which varies according to the geometry of the earthquake: scale, meridians and parallels are always provided. Maps are interactive: clicking on each intensity data point, the related information is displayed in the status bar. This feature was added to allow the identification of IDPs, especially in those cases for which the density of IDPs makes impossible labelling them all over the map.

The query by locality allows one to select a locality of interest from an alphabetical list, and to extract the seismic history either in tabular form, 
listing - in descending order - the intensities observed at sites and main earthquake parameters (date, epicentral area, epicentral intensity and magnitude), or as a diagram of intensity versus time. 2501 seismic histories are available, for those sites affected by at least five earthquakes (fig. 1b).

The whole database with its main variables (date and identity of earthquake, name, coordinates, intensity of the observed locality) is freely downloadable.

\section{CFTI, Catalogue of Strong Italian Earthquakes}

The Catalogue of Strong Italian Earthquakes is the result of several years of investigation performed by the ING-Istituto Nazionale di Geofisica, now Istituto Nazionale di Geofisica e Vulcanologia, in collaboration with the Italian firm SGA-Storia Geofisica Ambiente. Two versions of the catalogue were first published on CD-ROM, CFTI1 in 1995 (Boschi et al., 1995) and CFTI2 in 1997 (Boschi et al., 1997), while the online version CFTI2.1 was published in 1999 over the Internet (see Boschi et al., 2000).

CFTI is at the same time a parametric catalogue and a collection of original studies that provides intensity data and historical/critical commentaries for nearly one half of the earthquakes listed in the catalogue.

At the time of this survey, CFTI on the web, available on http://www.ingv.it/banchedati/ banche.html, covers the period 461 B.C. -1990 , and stores 31047 seismic effects regarding 11107 sites and 559 earthquakes, 29251 descriptive syntheses of the effects and 21178 bibliographic references. Download of the whole database is not yet available.

In the access menu of CFTI users find three main entry points: query by earthquake, by locality and by map (fig. 2).

Intensity data points and related information are accessed by the «query by earthquake» choosing the earthquake of interest in a list. This list can be the whole catalogue, or an extraction obtained specifying range values for date and intensity, and coordinates and radius for a rectangular or circular area. The web page with the retrieved data includes: the earthquake record with main parameters, a multiple choice list of available comments about the earthquake, the list of references, the list of observations with locality name, coordinates, and intensity at site. Both reference and observation lists can be easily saved on disk, for further use and analysis. The available comments can include several categories: information available in previous catalogues, state and development of earthquake review, effects in the social context, elements of local demography, concurrent natural and man-induced disasters, administrative/historical affiliation and boundaries, social and economic effects, institutional and administrative response, reconstructions and relocations, theories and observations, associated natural phenomena, major earthquake effects, effects on the environment, and full chronology of the earthquake sequence (fig. 2).

The query by locality allows one to extract the seismic histories of localities of interest, which can be selected over an alphabetical list or by a spatial query. The seismic history lists the event main parameters and intensity at site, and it is provided also as ASCII file ready to be saved to disk.

A set of ten historical maps of epicentres are available for defined time-periods showing administrative boundaries. Maps are interactive, providing for each plotted epicentre the relative information described above; together with each historical map, the web page lists also the earthquakes for that time-window, with main parameters and more details, e.g., reliability code of the estimate of the epicentral location.

\section{SISFRANCE ${ }^{\mathrm{TM}}$, Histoire et caractéristiques des séismes ressentis en France métropolitaine et sur ses abords}

Based on the SIRENE database (Lambert et al., 1996), the SISFRANCE ${ }^{\mathrm{TM}}$ database is co-produced by BRGM - Bureau de Recherches Géologiques et Minières, EDF - Electricité de France and IPSN - Institut de Protection et de Sûreté Nucléaire of France, which hold the intellectual rights, and promoted by the Ministère de l'Écologie et du Developement Durable. 


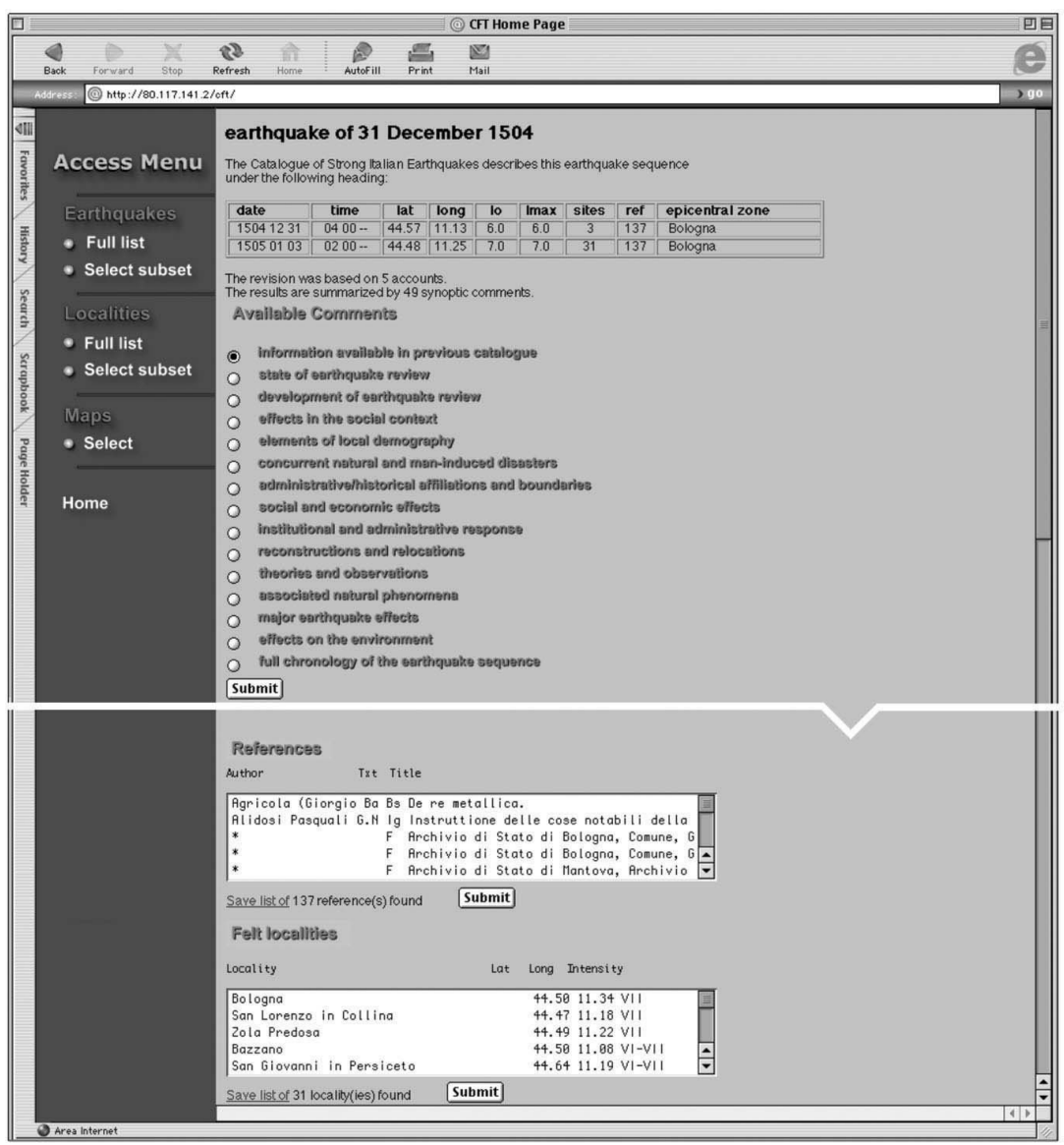

Fig. 2. CFTI query by earthquake.

Available at http://www.sisfrance.net since 2001, it covers the seismicity of French territory and bordering areas since 463 and since the end of 2002 it has been enriched with SISFRANCE-Antilles, covering a region between the South of Florida and French Guyana since 1495. Both databases are updated regularly. Download of whole datasets is not available, and large extractions of data are allowed upon agreement between users and co-producers.

SISFRANCE-metropolitaine contains 88000 observations referring to 6000 earthquakes in the time period 463-2001, and 9000 bibliographic references; SISFRANCE-Antilles contains
4900 IDPs referring to 2600 earthquakes in the French departments of Guadalupe, Martinique and French Guyane in the time period 14952001, plus 400 references.

Three types of query are available: i) spatial, by rectangular or circular area; ii) geographic, by province («département») and by locality («commune»); iii) by time-window («chronologie»). Queries of type i) and ii) can be refined by defining intensity range and/or time span. For each retrieved earthquake, its «identity» is summarized in a «card» providing date and type of event (aftershock, foreshock, main shock, or sequence), epicentral area, epi- 
central coordinates and epicentral intensities with associated reliability codes for values; the corresponding intensity data points are displayed on request in tabular form as the $« \mathrm{ob}-$ servations list», or are plotted on a macroseismic map (fig. 3). The list of observations, the map and the bibliographic references are always present as navigation options.

Lists of observations include for each locality: province or country, a reliability code for the assigned intensities, intensity at site in MSK, a code for other associated natural phenomena (earth movement, tsunami, hydrological and light effects, site effects), and coordinates of locality.

In the macroseimic map intensity data points are plotted as dots over a colour legend of intensities; a click on an IDP retrieves above described data. Macroseismic maps are dynamically generated by $\mathrm{MapX}^{\circledR}$, a module of Mapinfo Professional ${ }^{\circledR}$, the wide spread GIS software developed for Windows platform. Features of pan, zoom and info on a selected symbol typically embedded in most GIS software are therefore available.

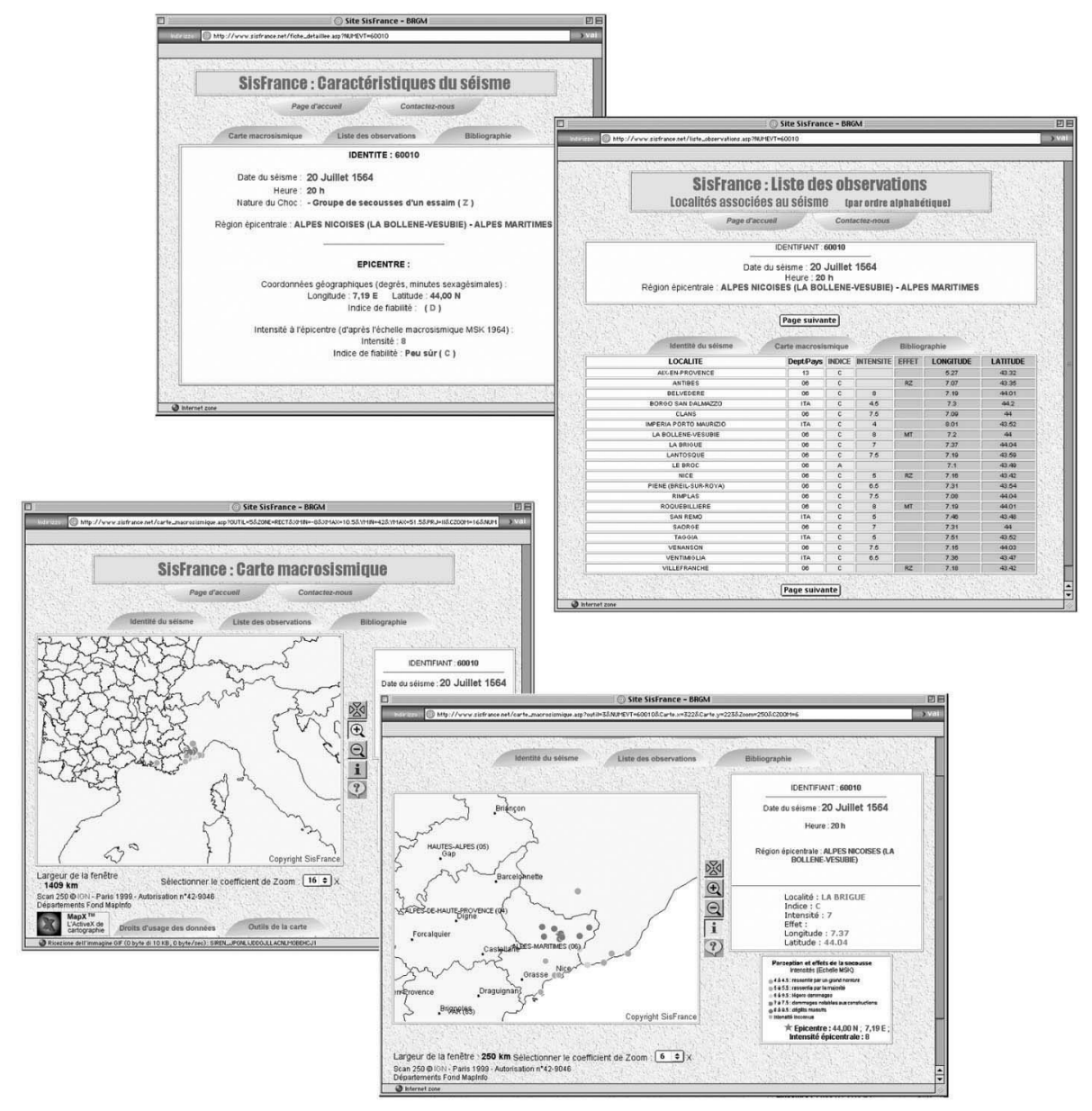

Fig. 3. SISFRANCE query by earthquake: main parameters of the event, IDP list and macroseismic map. 
Bibliographic references are listed for each earthquake; for some of them, original documents are provided as scanned images.

Query by locality retrieves a table of basic information of earthquakes that affected the selected locality, that is: time, epicentral area, present province/country of the epicentre, epicentral intensity and the observed intensity at site for each earthquake.

\section{ECOS, Earthquake Catalogue Of Switzerland}

The Macroseismic Earthquake Catalogue Of Switzerland - MECOS (1021-1999) was published over the Internet by the Swiss Seismological Service SED in 1999, followed by the Instrumental catalogue, IECOS (1975-2000) in 2001. ECOS, the current Earthquake Catalogue Of Switzerland (250-2002) published in 2002 and available at http://histserver.ethz.ch, is the result of a revision process performed during 1999-2002 (Fäh et al., 2003); its core consisting of the revised MECOS, called MECOS_02. ECOS covers the region included in the Swiss national map at the scale of 1:500.000 plus a buffer of $30 \mathrm{~km}$ (Swiss kmcoordinates: 460-882/20-350; Geographic coordinates: (in the region of 5.6-11.1E/45.4$48.3 \mathrm{~N}$ ); the completeness of the catalogue varies through time and region for different levels of magnitude. 26061 intensity points are available for 518 earthquakes.

Default query is by time-span or year, while the option «design your own catalogue» allows for tailoring query and customizing output: a query can be performed by time-window, moment magnitude and/or epicentral intensity range, and/or a rectangular or a circular area centred on a desired town identified by its post code. Data retrieved by default consist of date/time, earthquake type, historical certainty, geographic coordinates, place name, hypocentral depth, the SED moment magnitude, epicentral intensity and the data source; additional information can be chosen, such as the number of IDPs for the earthquake.

Once the desired earthquake and its parameters are retrieved, a click on «details» column fires the visualization of a page displaying in- formation regarding how and on the basis of which sources and agencies parameters have been assessed, and links to the macroseismic table, the macroseismic map and the bibliography (fig. 4).

The macroseismic table consists of list of IDPs, including for each locality: name, country, coordinates, a code identifying the source for IDPs, site quality, intensity in EMS-98; the table is also downloadable as a comma-separated values file.

Macroseimic maps are provided through a typical interface of Arcims, the widespread software by ESRI used to access and interact with Internet mapping and GIS data. A set of tools is available to visualize and query the plotted data: select which layer is visible and active for hot-linking, identifying, and making queries; the layers are: epicentre, site points, topography, main hydrography (rivers, lakes), country borders, towns; zoom, pan, measure, select by rectangle over a map, obtain attributes of a feature by clicking on it, query features based on their attribute values.

The catalogue - not the whole database - with related explanations, is downloadable.

\section{US Earthquake Intensity Database}

The US Earthquake Intensity Database is run by the National Geophysical Data Center of the National Oceanic and Atmospheric Administration and is available at http://www. ngdc.noaa.gov/seg/hazard/eqint.html/ It contains more than 157000 records referring to over 23000 US earthquakes in the time span 16381985, freely downloadable as a whole.

The database can be searched by specifying earthquake parameters, such as date, epicentre coordinates in a rectangular area, earthquake magnitude or intensity in Modified Mercalli Scale, or by specifying a locality by its name or coordinates.

Retrieved data include epicentral coordinates, magnitudes, focal depths, and name, coordinates, observed intensity and epicentral distance of the locality, and a code for the data source. For each retrieval, a description of the database format and legend of codes is presented at the bottom of the web page displaying results (fig. 5). 

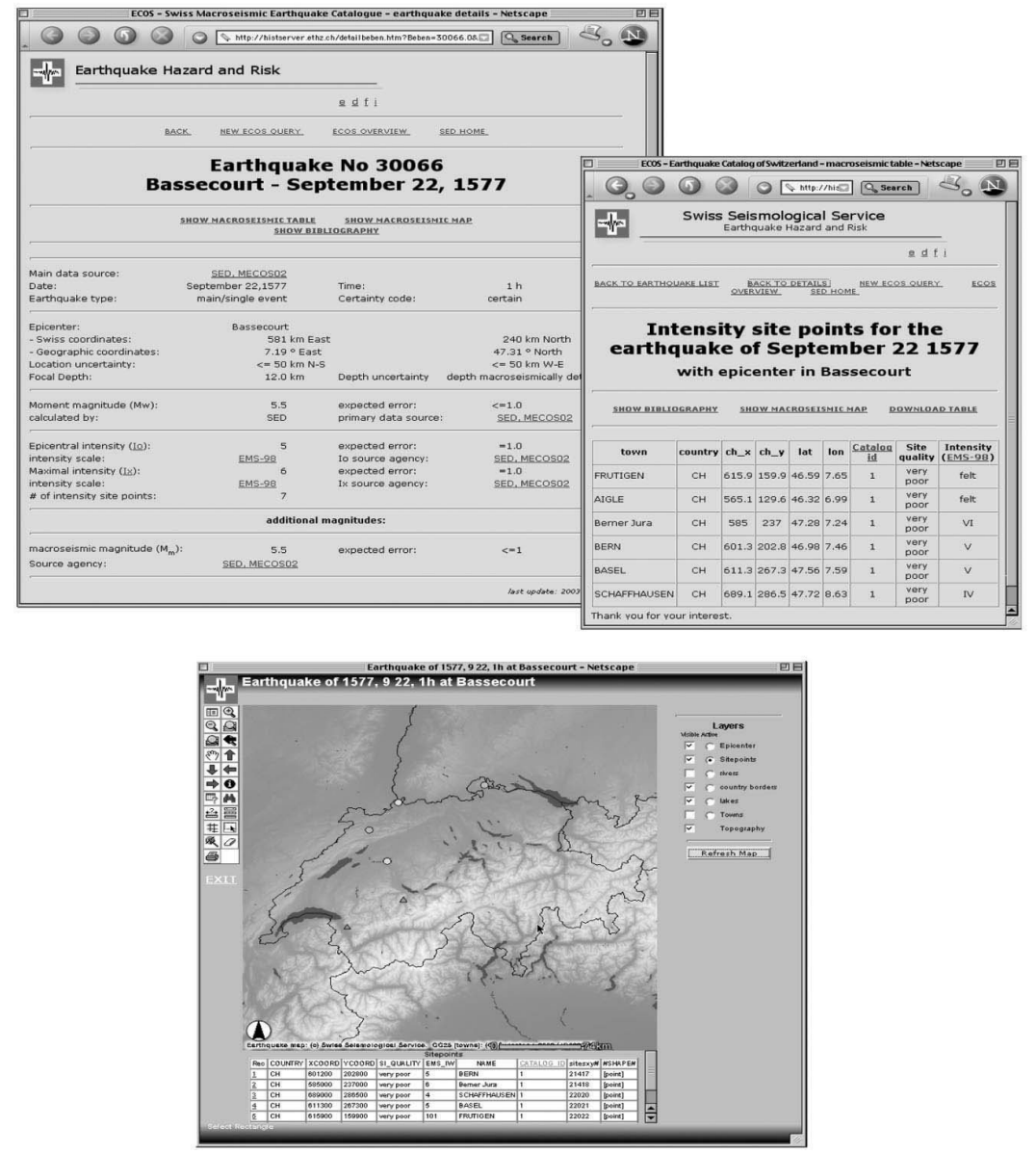

Fig. 4. ECOS query by earthquake: main parameters of the event, IDP list and macroseismic map.

7. CERESIS catalogue, Catálogo de intensidades para América del Sur

The CERESIS catalogue, released over the Internet in 1996 is presently run by CERESIS - Regional Center of Seismology for South America at http://www.ceresis.org/producto/intensi.htm/ Also referred as «Catálogo de terremotos para América del Sur» (CERESIS, 1985), it was compiled within the framework of the project SISRA, funded by Office of Foreign Disaster Assistance in the United States, through the U.S. Geological Survey.
Together with earthquake parameters, it stores up to 16000 intensity data points, referring to nearly 3000 South America earthquakes, covering globally the period 1520-1981 for the following countries: Argentina (1692-1985), Colombia (1566-1981), Brazil (1767-1981), Peru (1471-1981), Trinidad and Tobago (18251981), Chile (1730-1977), Bolivia (1650-1981), Ecuador (1541-1980), Venezuela (1530-1969).

In this compilation, however, intensity data points are intermingled with earthquake records and IDP records coming from different countries are not homogeneous. The whole data set 

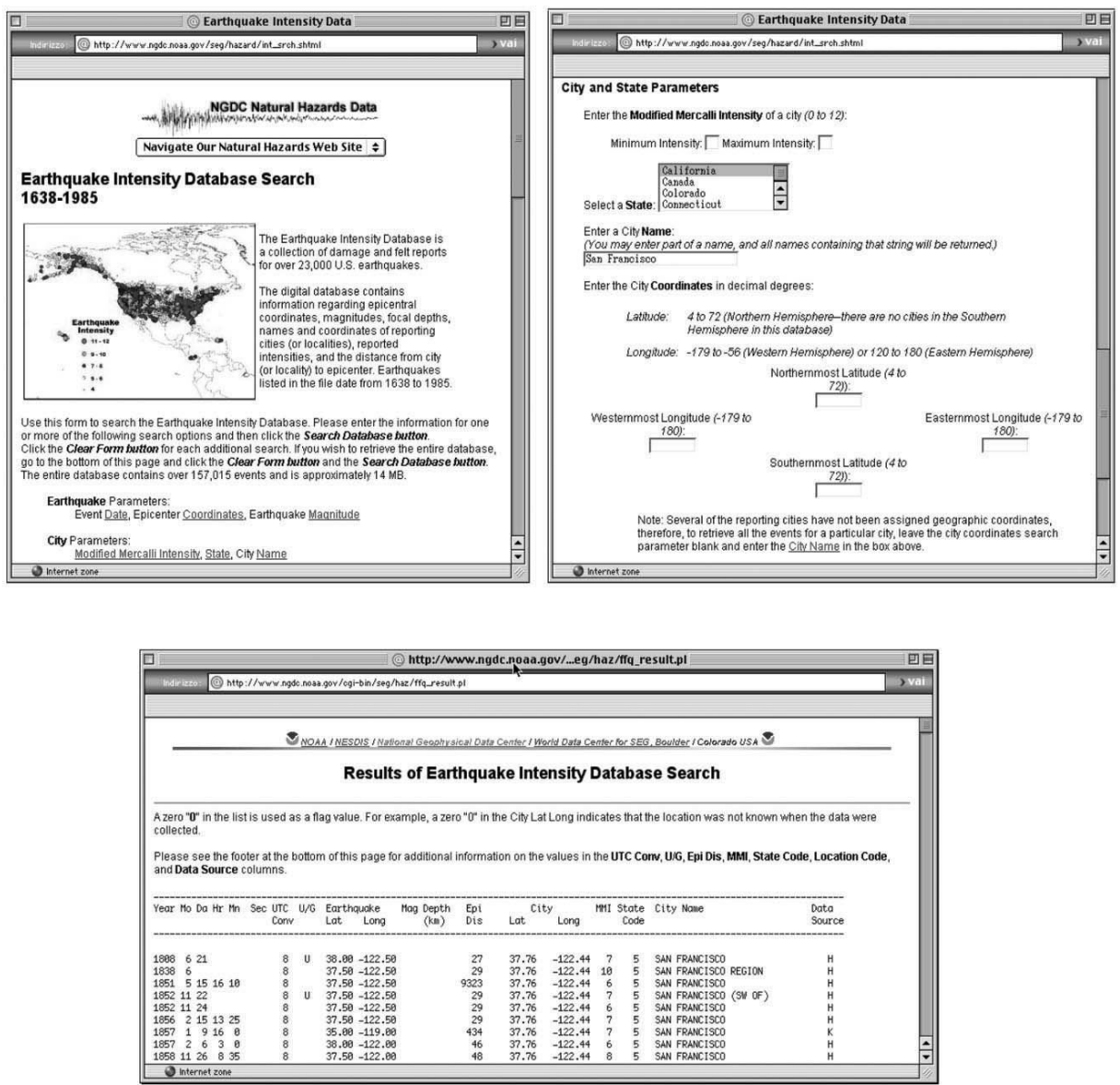

Fig. 5. US Intensity Database: main page, query by city and state parameters and related results.

(all countries) is downloadable as a zipped ASCII file. Data are formatted as flat files displayed on screen (fig. 6).

\section{EMID, European-Mediterranean Intensity Database}

The scope of EMID is to inventory the intensity data of earthquakes located in the Euro-Mediterranean region, put them together, compile the data according to a uniform standard and format, make them available to the public and keep them updated. This task is performed within the framework of the initiatives of the EMSC/CSEM Key Nodal Member for the dissemination of long-term seismicity data (Istituto Nazionale di Geofisica e Vulcanologia, Sezione di Milano), with the contribution of the investigators who supply intensity data.

Only a demo version for EMID is available on http://emidius.mi.ingv.it/EMID/ It hosts the IDPs for twenty selected earthquakes, in the time window 1400-1899 of the EuropeanMediterranean region, serving as a starting 
point for the implementation. The scheme to browse the data is the same of the online intensity database of damaging earthquakes in the Italian area, DOM. IDP lists and intensity maps are retrieved by «query by earthquake», clicking on an item of the earthquake list. As only a subset of IDPs is available, query by locality is not active yet. The presentation outlines the state of the art and main problems to cope with in homogenising the database, and it suggests a preliminary format for the compilation of EMID in a uniform way, as described in Stucchi et al. (2000).

For EMID implementation, the following procedures are envisaged: i) to perform a survey of existing data; ii) to analyse existing databases in order to cope with their differences; iii) to assess a reference standard format for both recompilation of existing IDPs and compilation of new ones; iv) to populate progressively the database with: homogenised IDPs for large earthquakes coming from datasets already structured (Italy, France, Switzerland), and data on recent events from field investigation and regional datasets as they will be compiled, with the aim of covering the main European regions for which seismic hazard is significant.

Through the web interface, it is foreseen that users will be able to: i) access data by earthquake to extract the intensity data points; ii) access by locality in order to provide seismic histories at the sites; iii) when possible, access the text - or abstract - of the study which provide the intensity data and the complete list of the historical sources used for the investigation; iv) obtain multiple views and representations of accessed data highlighting their relationships in space and time, e.g., maps of intensity distribution in the case of

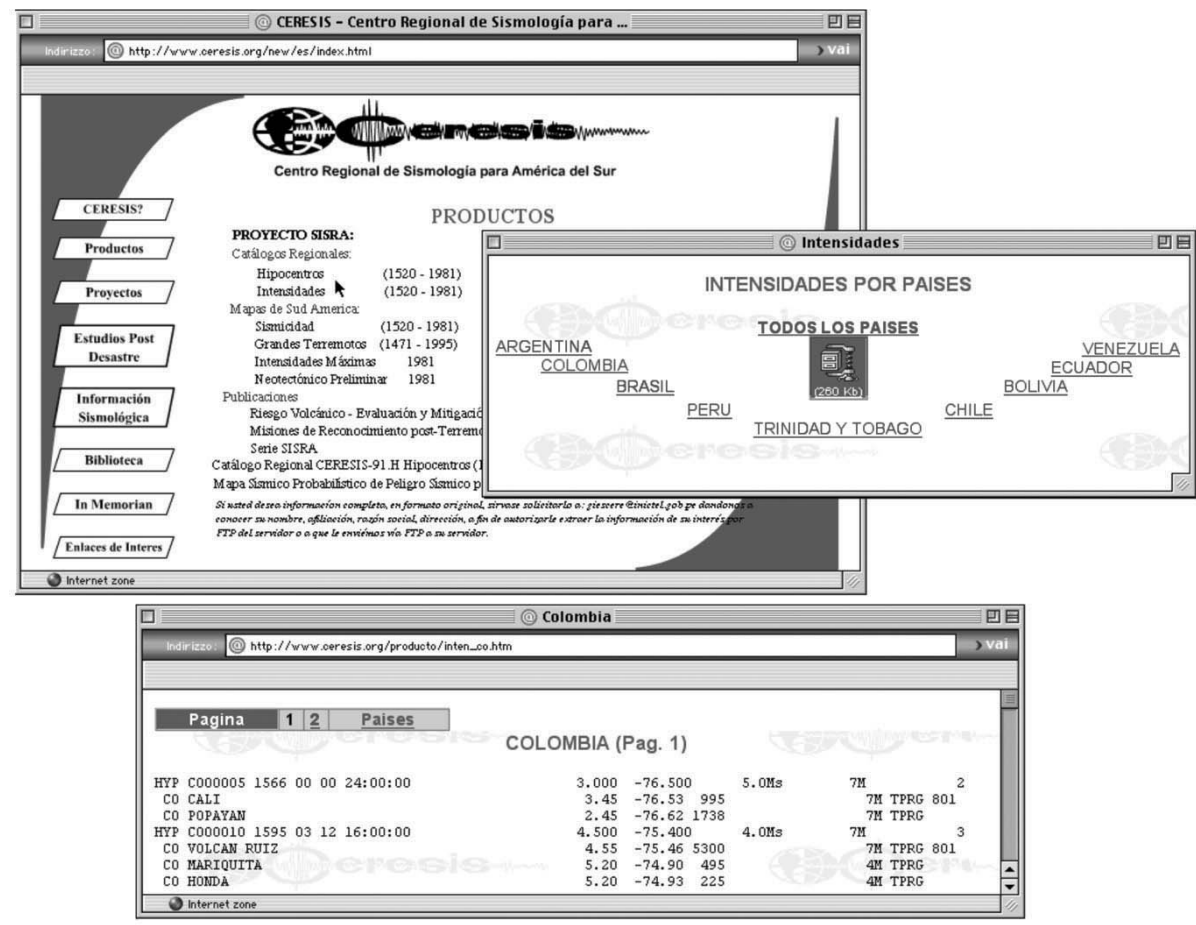

Fig. 6. CERESIS catalogue: entry point from the list of available countries, hypocentre parameters and IDPs for a selected country. 
Table II. Main features of the online available intensity databanks.

\begin{tabular}{cccccc}
\hline \hline Data bank & $\begin{array}{c}\text { Query by } \\
\text { earthquake }\end{array}$ & $\begin{array}{c}\text { Query by } \\
\text { locality }\end{array}$ & Studies & Maps & $\begin{array}{c}\text { Whole } \\
\text { download }\end{array}$ \\
\hline DOM & yes & yes & $(\times)$ & yes & yes \\
CFTI & yes & yes & yes & no & no \\
SISFRANCE & yes & yes & yes & yes & no \\
ECOS & yes & no & yes & yes & no \\
US & yes & yes & no & no & yes \\
CERESIS & no & no & no & no & yes \\
EMID & $(\times)$ & $(\times)$ & $(x)$ & $(\times)$ & $(\times)$ \\
\hline
\end{tabular}

(x) Planned facility.

query by earthquake and graphical seismic histories in the case of query by locality; v) easily save retrieved information to local disk, downloading in standard formats, in order to transfer data from the database to user's own programs.

With this premise, EMID should overcome both present heterogeneity and dispersion of the large amount of data which is currently produced in Europe, and users' difficulties in reaching this information, and offer a trans-national comprehensive homogeneous archive, freely accessible over the Internet, in which will be highly relevant to seismic hazard and risk studies (Stucchi, 2002).

\section{Conclusions}

A review of earthquake intensity databanks released over the Internet in the second half of the 1990's and currently available has been presented. Apart from NGDC/NOAA and CERESIS ones, which are trans-national datasets, covering U.S.A. and South America respectively, there are four online databases, DOM, CFTI, SISFRANCE, ECOS that cover three European countries (Italy, France, Switzerland), as results of compilation and dissemination activities performed on a national basis in the past. The establishment of a European intensity archive, outlined through the EMID prototype, within the initiative of EMSC, should serve as a starting point for a trans-national comprehensive resource in Europe.

With regard to the way by which these information products can be accessed on line, we find similarities and differences, which can be partly ascribed to design decisions and to limitations or benefits of available technology. The main features are summarized in table II.

Most of these web-based products provide two main options to search the data, «by earthquake» and «by locality». Those products that have been released earlier, e.g., the NGDC/NOAA earthquake intensity database, do not provide online intensity distribution mapping capabilities; in contrast these appear to be as a standard feature in those databases that have been recently released, e.g., SISFRANCE and ECOS, which exploit web-GIS technology. In some cases download of the whole IDP set is provided, in some others it is possible only to save IDPs for a single earthquake at a time, a feature that can affect user productivity. When sources of information are provided, they range from bibliographic references, macroseismic studies, to the historical sources themselves. This latter feature can be regarded as a special case of a credibility component, in the sense of Fogg (2002), as it allows users to have trust in the data, as it makes possible the back-tracing of the compilation procedures.

\section{REFERENCES}

Boschi, E., G. Ferrari, P. Gasperini, E. Guidoboni, G. SMriglio and G. VAlEnsise (Editors) (1995): Catalogo 
dei Forti Terremoti in Italia dal 461 a.C. al 1980 (ING, Roma - SGA, Bologna), pp. 973.

Boschi, E., E. Guidoboni, G. Ferrari, G. Valensise and P. GASPERINI (1997): Catalogo dei Forti Terremoti in Italia dal 461 A.C. al 1990 (ING, Roma - SGA. Bologna), pp. 644.

Boschi, E., E. Guidoboni, G. Ferrari, D. Mariotti, G. VAlEnsise and P. GASPERINI (2000): Catalogue of Strong Italian Earthquakes, Ann. Geofis., 43 (4), pp. 268 (with full database on CD-ROM).

CAMAssi, R. and M. STUCCHI (Editors) (1997): NT4.1: un Catalogo Parametrico di Terremoti di Area Italiana al di Sopra della Soglia di Danno (v. 4.1.1), (Milano), pp. 93 (on line: http://emidius.mi.ingv.it/NT/).

CERESIS (Centro Regional de Sismología para América del Sur) (1985): Catálogo de terremotos para América del Sur, Programa para la mitigación de los efectos de los terremotos en la región andina, Earthquake Mitigation Program in the Andean Region v. 1-9 (Project SISRA), edited by B. AsKew and S.T. AlgERMISSEN.

FäH, D., D. Giardini, F. Bay, F. Bernardi, J. Braunmiller, N. Deichmann, M. Furrer, L. Gantner, M. Gisler, D. ISENEGGER, M.J. JiMENEZ, P. KÄSTLI, R. Koglin, V. MASCIADRI, M. Rutz, C. Scheidegger, R. Schibler, D. Schorlemmer, G. Schwarz-Zanetti, S. Steimen, S. Sellami, S. WiEMER and J. WösSNER (2003): Earthquake Catalog Of Switzerland (ECOS) and the related macroseismic database, Eclogae Geol. Helv., 96/1.

FoGG, B.J. (2002): Stanford Guidelines for Web Credibility. A research Summary from the Standford Persuasive Tecnology Laboratory of the Stanford University (on line: http://www.web credibility.org/guidelines/
Gasperini, P., F. Bernardini, G. Valensise and E. Boschi (1999): Defining seismogenic sources from historical earthquake felt reports, Bull. Seismol. Soc. Am., 89, 94110.

Lambert J., A. Levret-Albaret, M. Cushing and C. Durouchoux (1996): Mille Ans de Séismes en France. Catalogue d'Epicentres Paramètres et Références (Ouest Editions, Nantes), pp. 75.

Monachesi, G. and M. StUCCHI (1997): DOM4.1, un database di osservazioni macrosismiche di terremoti di area italiana al di sopra della soglia del danno, Rapporto Tecnico (GNDT, Milano-Macerata), pp. 1052 (on line: http://emidius.mi.ingv.it/DOM/ home.html).

Mucciarelli, M., L. Peruzza and P. Caroli (2000): Tuning of seismic hazard estimates by means of observed site intensities, J. Earthquake Eng., 2, 141-159.

Padula, M. and G. Rubbia Rinaldi (1999): Mission-critical Web applications: a seismological case, Interactions, 4, 53-65.

STUCCHI, M. (2002): A European-Mediterranean database of historical earthquake data for the assessment of long-term seismic hazard, in Proceedings of EUMEDIN Workshop on Natural and Technological Hazard Research in Europe: 'Contribution to MEDIN', edited by K. FABBRI and M. YeroYANNI, Bruxelles, 15-16 November 2000, 70-77.

Stucchi, M., P. Albini and G. Rubbia Rinaldi (2000): Historical earthquake data in Europe and the EuroMediterranean Intensity Database, Euro-Mediterranean Seismological Centre Newsletter, 16, 5-7 (on line: http://www.emsc-csem.org/). 